\title{
SISTEM PENDUKUNG KEPUTUSAN DALAM PEMBERIAN BONUS BERDASARKAN PENILAIAN KINERJA KARYAWAN PADA CV. ABC DENGAN MENGGUNAKAN METODE ANALITYCAL HIERARCHY PROCESS (AHP)
}

\author{
Baringin Sianipar $^{1}$, Dedi Candro Parulian Sinaga ${ }^{2}$ \\ Teknik Rekayasa Komputer Jaringan ${ }^{1}$, Teknik Rekaya Komputer Jaringan ${ }^{2}$ \\ STMIK Pelita Nusantara ${ }^{1}$, STMIK Pelita Nusantara ${ }^{2}$ \\ aniparbaringin87@gmail.com¹, dedisinaga27@gmail.com²
}

\begin{abstract}
ABSTRAK
Pada setiap perusahaan, instansi, organisasi atau badan usaha akan memberikan gaji sebagai kompensasi dari kerja seorang karyawan, disamping pemberian gaji pokok pada karyawannya, setiap instansi seringkali memberikan bonus disamping gaji pokok untuk memacu kinerja dan produktivitas kerja karyawannya. Adapun cara yang pemberian bonus yang digunakan adalah dengan melakukan penilaian terhadap karyawan yang sesuai kriteria oleh pimpinan, bonus akan diberikan setelah dilakukan evaluasi penilaian terhadap karyawan setiap tahunnya. Adapun kriteria yang akan digunakan untuk menentukan karyawan yang memiliki prioritas agar mendapatkan bonus meliputi kehadiran, penampilan, kedisiplinan, komunikasi, kerjasama. Selain masih menggunakan sistem konvensional, kedekatan pimpinan dan karyawan seringkali menghasilkan keputusan yang berbeda dari yang semestinya hal ini menyebabkan hasil keputusannya menjadi tidak tepat. Adapun permasalahan dalam penelitian ini adalah bagaimana membangun sistem pendukung keputusan menggunakan metode Analytical Hierarchy Process (AHP). Metode ini dipilih untuk membantu pimpinan perusahaan untuk menentukan siapa karyawan yang berhak menerima bonus tahunan berdasarkan kriteria yang sudah ditentukan.
\end{abstract}

Kata Kunci : Metode Analitycal Hierarchy Process (AHP), Sistem Pendukung Keputusan, Bonus Karyawan

\begin{abstract}
In each company, agency, organization or business entity will provide a salary as compensation for the work of an employee, in addition to providing basic salary to employees, each agency often provides a bonus in addition to the basic salary to boost the performance and work productivity of its employees. The method for giving bonuses is by evaluating employees who meet the criteria by the leadership, bonuses will be given after an annual evaluation of the employee's assessment. The criteria that will be used to determine which employees have priority in order to get bonuses include attendance, appearance, discipline, communication, cooperation. In addition to still using conventional systems, the closeness of leaders and employees often results in decisions that are different from what they should be. This causes the results of their decisions to be incorrect. The problem in this research is how to build a decision support system using the Analytical Hierarchy Process (AHP) method. This method was chosen to help company leaders determine which employees are entitled to receive an annual bonus based on predetermined criteria.
\end{abstract}

Keywords: Analitycal Hierarchy Process (AHP) Method, Decision Support Systems, Employee Bonuses

\section{PENDAHULUAN}

\subsection{Latar Belakang Masalah}

Perkembangan teknologi informasi pada saat ini berkembang dengan pesat, sehingga sangat mudah untuk mendapatkan informasi. Komputer selalu menghadirkan kemudahan pada setiap perkembangannya, dan dapat membantu mengolah data sehingga pekerjaan dapat diselesaikan dengan cepat dan efektif. Kegunaan komputer bukan hanya sebagai penyimpan dan pengolahan data saja, melainkan mampu mengkaji informasi untuk setiap pengguna, sehingga dapat menyediakan pilihan untuk mendukung pengambilan keputusan yang dapat dilakukan.

Dalam proses pemilihan pemberian bonus kepada karyawan. HRD CV. ABC mengalami banyak kendala yang dihadapi, diantaranya kesulitan dalam memilih karyawan yang layak untuk diberikan bonus tahunan dengan banyaknya kriteria sebagai penilaian, dan kendala yang lain

JISICOM (Journal of Information System, Informatics and Computing)

http://journal.stmikjayakarta.ac.id/index.php/jisicom Telp.+62-21-3905050, e-mail: jisicom@stmikjayakarta.ac.id, jisicom2017@gmail.com 
adalah pimpinan $\mathrm{CV}$. $\mathrm{ABC}$ mengharapkan hasil dari proses pemilihan tersebut, yaitu karyawan yang diprioritaskan untuk mendapat bonus utama segera dilaporkan, sedangkan pada pihak Personalia tidak saja menangani permasalahan karyawan tetapi juga serangkaian tugas yang berkaitan dengan permasalahan perusahaan lainnya. Untuk membantu Personalia CV. ABC untuk mengambil keputusan karyawan yang diprioritaskan mendapat bonus tahunan di perusahaan diperlukan suatu sistem keputusan. Sistem pendukung keputusan ini akan membantu personalia untuk menganalisa karyawan yang diprioritaskan untuk mendapat bonus.

Selama ini CV. ABC memberikan bonus pada karyawan, dan saat ini masih dilakukan secara manual. Dengan mengecek satu persatu kriteria yang dijadikan pedoman dalam pengambilan keputusan berapa banyak bonus yang akan diberikan kepada karyawan setiap tahunnya. Oleh karena itu, dibutuhkan suatu sistem yang dapat membantu pihak perusahaan dalam pengambilan keputusan berdasarkan kriteria tersebut. Adapun metode yang akan digunakan dalam sistem pendukung keputusan ini adalah Metode Analytic Hierarchy Process (AHP). Metode ini merupakan solusi terbaik dengan memanfaatkan perbandingan berpasangan (pairwise comparison) sebagai dasar menentukan pilihan.

\section{METODE DAN MATERI}

2.1 Perumusan Masalah

Berdasarkan latar belakang masalah di atas, maka dalam penelitian ini yang dibahas adalah Bagaimana penerapan metode AHP dalam pemberian bonus berdasarkan penilaian kinerja karyawan.

\subsection{Landasan Teori}

a. Sistem Pendukung Keputusan

Menurut James O'Brien dan George M. Marakas (2014) "Sistem pendukung keputusan merupakan sebuah sistem informasi yang menggunakan model keputusan, sebuah database dan sebuah wawasan dari pembuat keputusan dalam sebuah proses pemodelan yang ad hoc dan interaktif untuk mencapai sebuah keputusan yang spesifik oleh seorang pembuat keputusan yang spesifik."

Menurut Kusrini (2017) "Sistem Pendukung Keputusan merupakan sistem informasi interaktif yang menyediakan informasi, permodelan dan manipulasi data. Sistem itu digunakan untuk membantu pengambilan keputusan dalam situasi yang semi terstruktur dan situasi tidak terstruktur, dimana tak seorang pun tahu secara pasti bagaimana keputusan seharusnya dibuat”.

Menurut D.C.P. Sinaga (2020) "Sistem pendukung keputusan bukan merupakan alat pengambilan keputusan, melainkan merupakan sistem yang membantu pengambil keputusan dengan melengkapi mereka dengan informasi dari data yang telah diolah dengan relevan dan diperlukan untuk membuat keputusan tentang suatu masalah dengan lebih cepat dan akurat".

\subsection{Metode Analytical Hierarchy Process (AHP)}

Menurut (Kusrini, 2017 : 133), Pada dasarnya, proses pengambilan keputusan adalah memilih suatu alternatif. Peralatan utama AHP adalah sebuah hierarki fungsional dengan input utamanya persepsi manusia. Keberadaan hierarki memungkinkan dipecahnya masalah kompleks atau tidak terstruktur dalam sub-sub masalah, lalu menyusunnya menjadi suatu bentuk hierarki. AHP memiliki banyak keunggulan dalam menjelaskan proses pengambilan keputusan. Salah satunya adalah dapat menjelaskan proses pengambil keputusan.

Menurut (Nofriansyah, 2016) Analytical Hierarchy Process adalah salah satu metode dalam sistem pendukung keputusan yang memiliki keunikan di bandingkan yang lainnya. Hal ini dikarenakan dalam pembobotan kriteria, bobot dari setiap kriteria bukan ditentukan di awal tetapi ditentukan menggunakan rumus dari metode ini berdasarkan skala prioritas (tingkat kepentingan).

\section{PEMBAHASA DAN HASIL}

\subsection{Tahapan Penilitian}

Tahapan penelitian yaitu tahapan yang akan dilakukan untuk mempermudah dalam melakukan penelitian. Metode yang mendukung dalam sistem pendukung keputusan dalam pemberian bonus berdasarkan penilaian kinerja karyawan pada PT Saras Bintang Abadi dengan menggunakan metode Analytical Hierarchy Process (AHP) selain modul pemberian bonus pada karyawan menggunakan metode AHP, sistem informasi ini terdapat modul perangkingan. Aplikasi yang digunakan adalah Microsoft Access yang berguna untuk membuat, mengolah, dan mengelola basis data atau lebih 
dikenal dengan database. Database adalah kumpulan arsip data berbentuk tabel yang saling berkaitan untuk menghasilkan informasi. Data digunakan sebagai masukan yang akan diolah menjadi informasi.

\begin{tabular}{|l|l|c|l|}
\hline No & Kriteria & Kode & Keterangan \\
\hline 1 & Penampilan & K1 & Penilaian penampilan. \\
\hline 2 & Kehadiran & K2 & $\begin{array}{l}\text { Penilaian dari segi } \\
\text { kehadiran. }\end{array}$ \\
\hline 3 & Kedisiplinan & K3 & $\begin{array}{l}\text { Penilaian yang dilihat } \\
\text { dari segi kedisiplinan. }\end{array}$ \\
\hline 4 & Kerjasama & K4 & $\begin{array}{l}\text { Penilaian yang dilihat } \\
\text { dari segi kualitas } \\
\text { interpersonal skills } \\
\text { serta orientasi kerja } \\
\text { karyawan baik } \\
\text { individual maupun } \\
\text { kelompoknya. }\end{array}$ \\
\hline 5 & Komunikasi & K5 & $\begin{array}{l}\text { Penilian dari segi } \\
\text { komunikasi karyawan } \\
\text { dalam bekerja. }\end{array}$ \\
\hline
\end{tabular}

Tabel 3.1 Kriteria-Kriteria Penilaian

Setiap implementasi metode AHP dalam perancangan sistem tersebut adalah untuk mengetahui karyawan yang ada yang nantinya dapat menerima bonus sesuai dengan penilaian kerja. Adapun nama alternatif pemberian bonus karyawan dapat dilihat pada tabel dibawah ini :

\begin{tabular}{|l|l|l|}
\hline No & Alternatif & Nama Karyawan \\
\hline 1 & A1 & Chiki \\
\hline 2 & A2 & Wahyu \\
\hline 3 & A3 & Mahendra \\
\hline 4 & A4 & Susi \\
\hline 5 & A5 & Hasbi \\
\hline
\end{tabular}

Tabel 3.2 Alternatif Pemberian Bonus

\subsection{Menentukan Masalah Dan Prioritas Kriteria}

Berdasarkan data yang diperoleh tentang hal prioritas kriteria yaitu, K1 (Penampilan) dan K2 (Kehadiran) merupakan kriteria dengan bobot tertinggi atau prioritas utama, kemudian K3 (Kedisiplinan) merupakan prioritas kedua, serta K4 dan K5 merupakan prioritas terakhir. Maka masalah diatas dapat di dekomposisikan kedalam tangga prioritas seperti gambar dibawah ini :

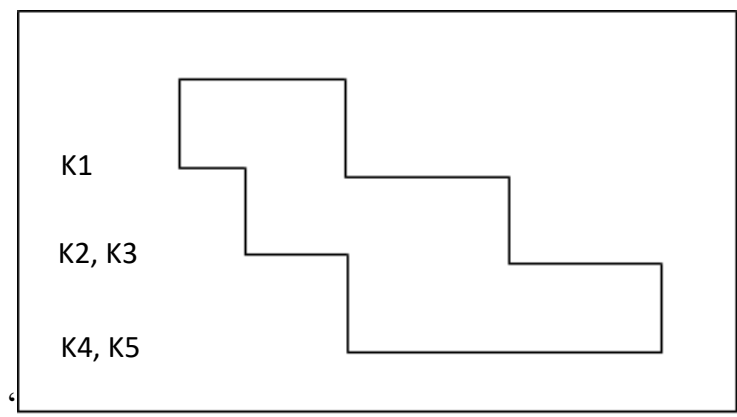

Gambar 3.1 Tangga Prioritas Kriteria Metode AHP

3.3 Membuat Matriks Perbandingan Berpasangan

Sebelum menghitung nilai matriks perbandingan berpasangan, terlebih dahulu menentukan penilaian atau properti pada masing-masing alternatif berdasarkan nilai yang telah ditentukan oleh $\mathrm{CV}$. $\mathrm{ABC}$.

\begin{tabular}{|c|l|c|c|c|c|c|}
\hline \multirow{2}{*}{ No } & Nama & \multicolumn{5}{|c|}{ Unsur Yang Dinilai } \\
\cline { 2 - 7 } & Pegawai & K1 & K2 & K3 & K4 & K5 \\
\hline 1 & Chiki & 71 & 89 & 83 & 86 & 76 \\
\hline 2 & Wahyu & 80 & 68 & 70 & 88 & 88 \\
\hline 3 & Mahendra & 85 & 80 & 78 & 85 & 87 \\
\hline 4 & Susi & 75 & 70 & 70 & 89 & 86 \\
\hline 5 & Hasby & 77 & 85 & 90 & 90 & 80 \\
\hline \multicolumn{6}{|c|}{ Tabel 3.3 Penilaian Alternatif } \\
\hline
\end{tabular}

Tahap yang harus dilakukan yaitu menghitung nilai Pairwise Matrix (Matrix Perbandingan Berpasangan) antar criteriawihgt - bobot dan memberikan penilaian terhadap elemen yang dibandingkan dalam matriks. Berikut ini adalah tabel matriks perbandingan berpasangan dari kriteria yaitu sebagai berikut :

\begin{tabular}{|llllll|}
\hline & $\mathrm{K} 1$ & $\mathrm{~K} 2$ & $\mathrm{~K} 3$ & $\mathrm{~K} 4$ & $\mathrm{~K} 5$ \\
\hline $\mathrm{K} 1$ & $1 / 1$ & $1 / 3$ & $1 / 3$ & $1 / 5$ & $1 / 5$ \\
\hline $\mathrm{K} 2$ & $3 / 1$ & $3 / 3$ & $3 / 3$ & $3 / 5$ & $3 / 5$ \\
\hline $\mathrm{K} 3$ & $3 / 1$ & $3 / 3$ & $3 / 3$ & $3 / 5$ & $3 / 5$ \\
\hline $\mathrm{K} 4$ & $5 / 1$ & $5 / 3$ & $5 / 3$ & $5 / 5$ & $5 / 5$ \\
\hline $\mathrm{K} 5$ & $5 / 1$ & $5 / 3$ & $5 / 3$ & $5 / 5$ & $5 / 5$ \\
\hline
\end{tabular}

Tabel 3.4 Matrix Perbandingan Berpasangan

4.1 Tampilan Sistem

a. Halaman Login

JISICOM (Journal of Information System, Informatics and Computing)

http://journal.stmikjayakarta.ac.id/index.php/jisicom Telp.+62-21-3905050, e-mail:jisicom@stmikjayakarta.ac.id, jisicom2017@gmail.com 


\section{Journal of Information System, Informatics and Computing}

Vol.4 No.2, Desember 2020

e-ISSN : 2597-3673 (Online)

p-ISSN : 2579-5201 (Printed)

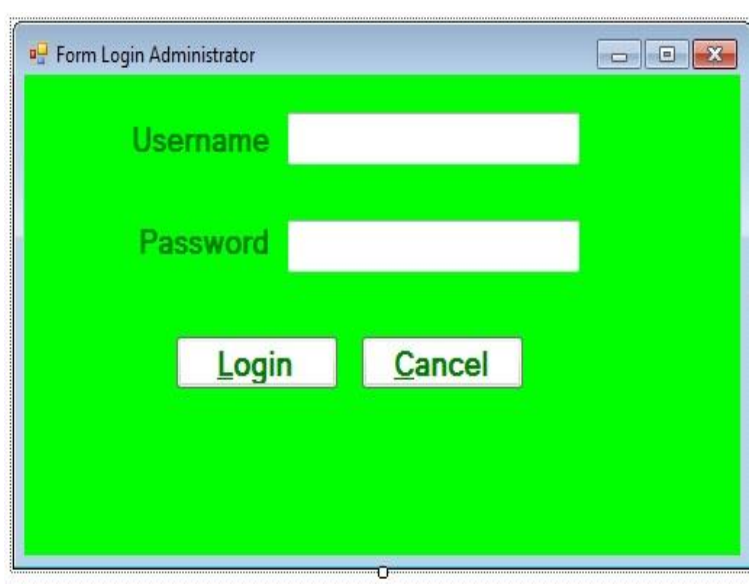

Gambar 4.1 Halaman Login

b. Halaman Menu Utama

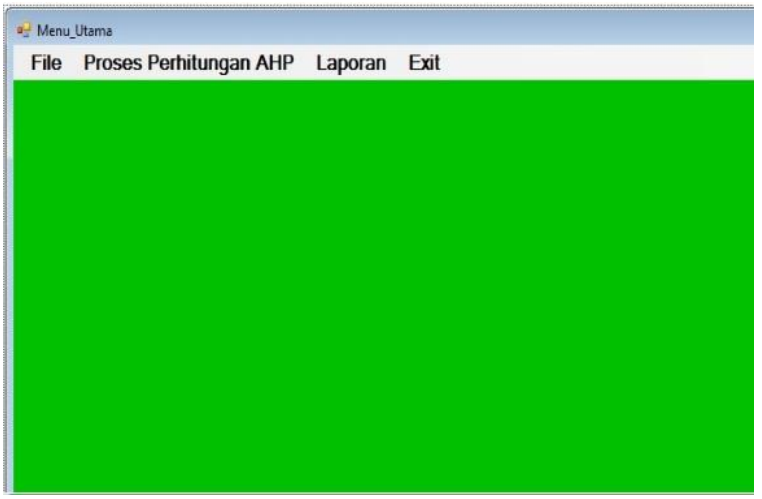

Gambar 4.2 Halaman Menu Utama

c. Halaman data Pegawai

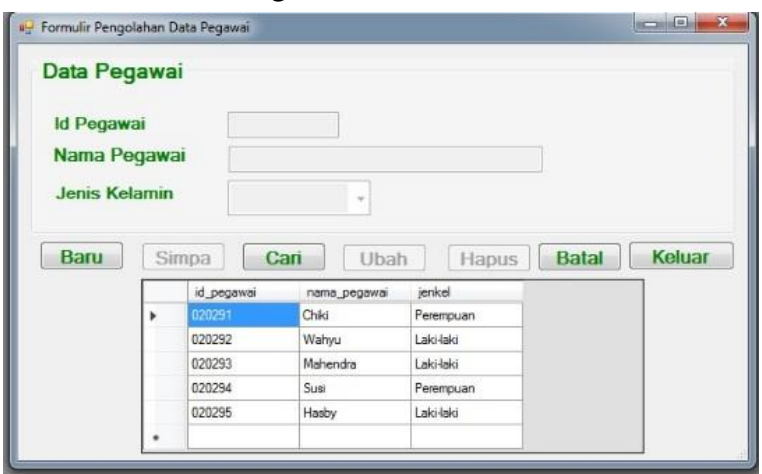

Gambar 4.3 Halaman data Pegawai

d. Halaman Data Kriteria Pegawai

4.4 Gambar Data Kriteria Pegawai

e. Halaman Hasil Nilai Kriteria Pegawai

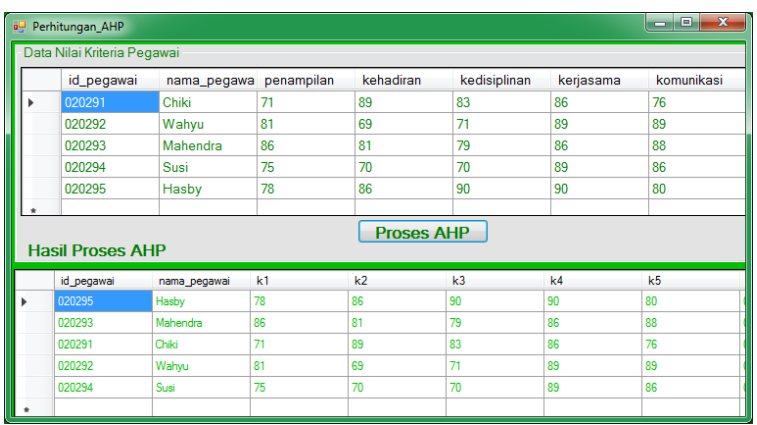

Gambar 4.5 Proses AHP

f. Gambar Laporan Data Pegawai

\begin{tabular}{lll}
\hline 12/32020 & \multicolumn{2}{c}{ DATA PEGAWAl } \\
\hline \hline id_pegawai & nama_pegawai & jenkel \\
\hline 020291 & Chiki & Perempuan \\
\hline 020292 & Wahyu & Laki-aki \\
\hline 020293 & Nahendra & Laki-aki \\
\hline 020294 & Susi & Perempuan \\
\hline 020295 & Hasby & Laki-aki \\
\hline
\end{tabular}

Gambar 4.6. Gambar Laporan Data Pegawai

4.6. Laporan Data Kriteria

\begin{tabular}{|c|c|c|c|c|c|c|}
\hline 12332000 & & LAPORAN & TA ANLAN KR & NTERA & & \\
\hline id penawai & nama pecawai & Denampilan & kehadiran & kedispilinan & keriassama & komunikasi| \\
\hline 0029 & Chiki & 71 & 89 & 83.00 & 86.00 & 76.00 \\
\hline 00202 & Wanyu & 81 & 69 & 71.00 & 89.00 & 89.0 \\
\hline 00203 & Malendra & 86 & 81 & 79.00 & 860.00 & 88.00 \\
\hline 00024 & Sulsi & 75 & 70 & 70.00 & 89.00 & 8600 \\
\hline 00025 & Hasoly & 78 & 86 & 90.00 & 90.00 & 80.00 \\
\hline
\end{tabular}

Gambar 4.6. Laporan Data Kriteria

4.7. Laporan Data Perhitungan AHP

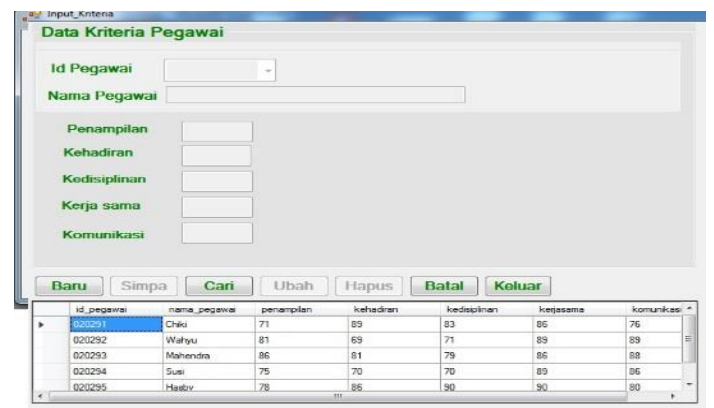

JISICOM (Journal of Information System, Informatics and Computing)

http://journal.stmikjayakarta.ac.id/index.php/jisicom Telp.+62-21-3905050, e-mail:jisicom@stmikjayakarta.ac.id, jisicom2017@gmail.com 


\begin{tabular}{|c|c|c|c|c|c|c|c|}
\hline 12332020 & & & N PERH & INGANN & AlAHP & & \\
\hline id pegawai & nama pegawai & $\mathrm{k1}$ & $\mathrm{k} 2$ & $k_{3}^{3}$ & $\mathrm{k4}$ & $k 5$ & nilaiahp \\
\hline 020295 & Hasboy & 78.00 & 86.00 & 9000 & 9000 & 80.00 & 0,2069 \\
\hline 020293 & Mahendra & 86.00 & 81.00 & 79.00 & 860.00 & 88.00 & 0,2039 \\
\hline 020291 & Chiki & 71.00 & 89.00 & 83.00 & 86.00 & 76.00 & 0,1985 \\
\hline 020292 & Wahyu & 81.00 & 69.00 & 71.00 & 89.00 & 89.00 & 0,1969 \\
\hline 020294 & Susi & 75.00 & 70.00 & 70000 & 89.00 & 880.00 & 0,1938 \\
\hline
\end{tabular}

Gambar 4.7. Laporan Data Perhiungan AHP

\section{REFRENSI}

Disusun dan diberi nomor urut berdasarkan urutan kutipan. Penulisan pustaka: nama penulis (tanpa gelar), tahun, judul, penerbit, dan kota penerbit. Berikut adalah contoh penulisan daftar pustak/referensi:

[1] F. A. Sianturi, "Implementasi Sistem Pendukung Keputusan Kenaikan Jabatan Guru Dengan Model Profile Matching Pada Sekolah Sma Swasta Raksana Medan,” Mantik Penusa, 2015.

[2] Kristiyanti, D. A. (2017). Sistem Pendukung Keputusan Seleksi Karyawan Untuk Jabatan Tertentu Dengan Pendekatan Analisa Gap Profile Matching, 19(1), 20-29.

[3] Stevanus, R., Handayani, R. I., \& Kristiyanti, D.A.(2018). Laporan Akhir Penelitian - Sistem Pendukung Keputusan Pemberian Bonus Karyawan Menggunakan Metode AHP Pada Rumah Sakit Buah Hati Ciputat. Jakarta.

[4] I. Parlina et al., "Naive Bayes Algorithm Analysis to Determine the Percentage Level of visitors the Most Dominant Zoo Visit by Age Category," Journal of Physics: Conference Series, vol. 1255, no. 1, pp. 1-5, 2019.

[5] H. Siahaan, H. Mawengkang, S. Efendi, A. Wanto, and A. Perdana Windarto, "Application of Classification Method C4.5 on Selection of Exemplary Teachers," Journal of Physics: Conference Series, vol. 1235, no. 1, pp. 1-7, Jun. 2019

[6]S. Setti, A. Wanto, M. Syafiq, A. Andriano, and B. K. Sihotang, "Analysis of Backpropagation Algorithms in Predicting World Internet Users," Journal of Physics: Conference Series, vol. 1255, no. 1, pp. 1-6, 2019.

[7] DCP Sinaga, B Sianipar, P Marpaung, "Pemilihan Calon Manager Dari Pegawai Berprestasi Menggunakan Metode ProfileMatching Pada CV. Glofacia Oceanic", Volume 4 Nomor 2, September 2020, pp. 643-656 ISSN: 2548-9771/EISSN: 2549-7200

[8]W. Saputra, J. T. Hardinata, and A. Wanto, "Resilient method in determining the best architectural model for predicting open unemployment in Indonesia," IOP Conference Series: Materials Science and Engineering, vol. 725, no. 1, pp. 1-7, 2020.

JISICOM (Journal of Information System, Informatics and Computing)

http://journal.stmikjayakarta.ac.id/index.php/jisicom Telp.+62-21-3905050, e-mail: jisicom@stmikjayakarta.ac.id, jisicom2017@gmail.com 